\title{
L etras
}




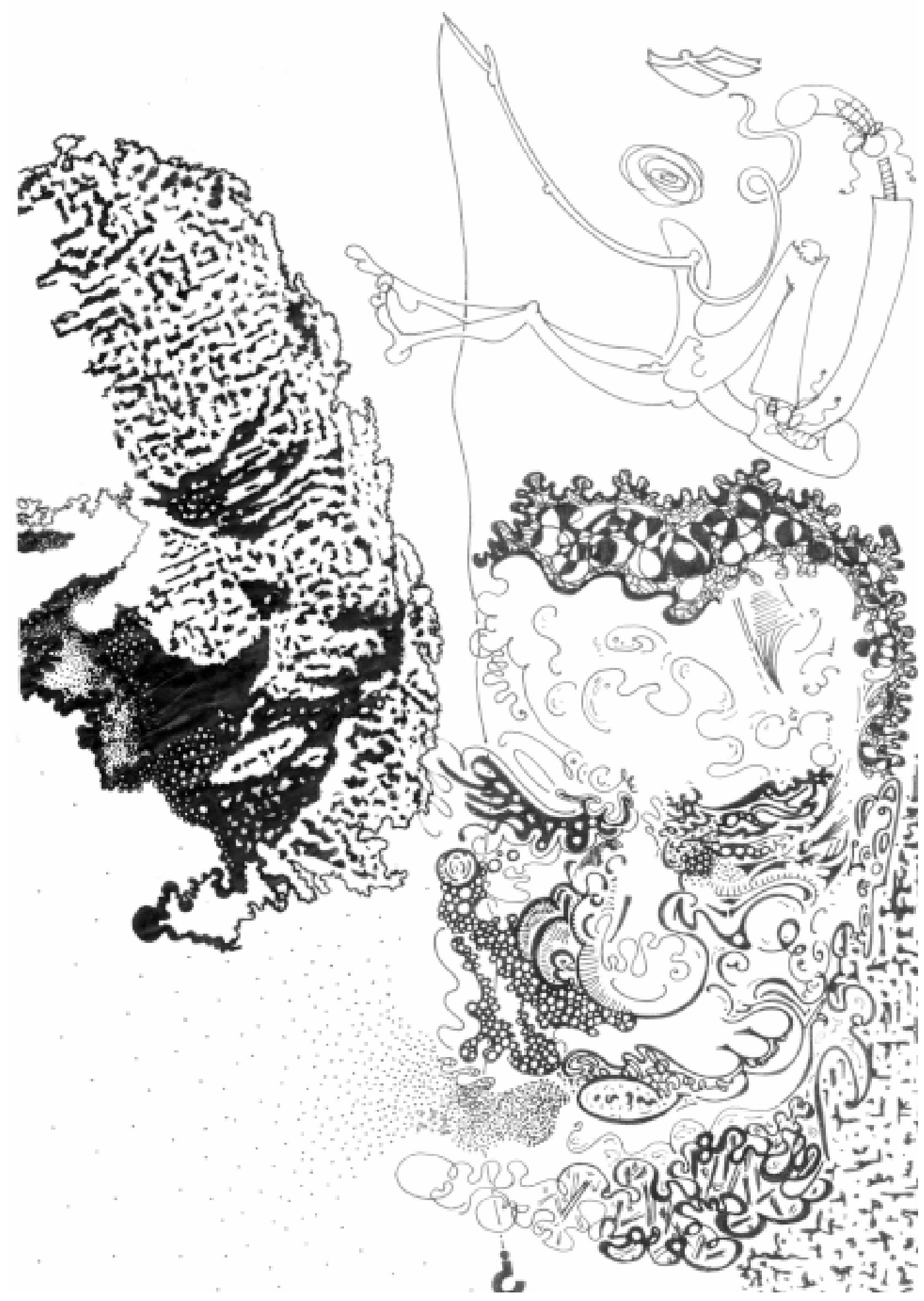

I lustração de Carolina di Paolo baseada na máscara mortuária de M achado de A ssis. 


\title{
D uas montanhas, quatro abismos: as "filosofias da natureza" de Victor H ugo e M achado de Assis
}

\author{
R AVEL GIORDANOPAZ
}

\section{Introdução}

La langoureuse Asie et la brûlante Afrique,

Tout un monde lointain, absent, presque d'efunt, Vit dans tes profondeurs...

C harles Baudelaire, "La chevelure"

A

OBRA DE MACHADO DE ASSIs é uma dessas cuja riqueza de elementos permite que se extraia, como se diz, um pouco de tudo, e sempre um pouco mais. Basta conferir o que se tem produzido, a partir dela, em termos de leituras históricas, sociológicas, psicológicas e filosóficas, análises estruturais e estudos de fontes e influências (1). É bobagem tentar definir prioridades no que diz respeito a essas questões, mas essa perspectiva a que chamamos de filosófica certamente tem um papel importante na compreensão global da poética do escritor. Por isso, inclusive, ela não se faz presente apenas em abordagens especificamente filosóficas, mas perpassa quase toda a crítica machadiana: para citarmos um exemplo significativo, o ultra-sociológico estudo de Faoro possui um capítulo brilhante ("Pandora - do demoníaco ao diabólico") dedicado a ela, e, mais do que isso, a uma de suas vertentes mais radicais. Pois o fato é que também no que diz respeito a essa questão a variedade de elementos que $M$ achado integra a sua obra exige que se façam algumas distinções, por relativas que sejam: nesse sentido, a construção de uma certa "filosofia social", que o escritor realiza, entre outras coisas, a partir de leituras de autores como os estóicos ou os moralistas franceses, pode ser pelo menos provisória e parcialmente distinta do que chamaríamos uma "filosofia da natureza" machadiana, na qual influências diversas, que vão de Santo Agostinho a Schopenhauer - mas que têm no diálogo com o Romantismo uma de suas fontes principais -, ajudam a compor uma interpretação particular das questões fundamentais da vida e da morte, do caos e do cosmos.

Assim, a perspectiva a que nos referimos diz respeito àquilo que se pode denominar a "dimensão profunda" do olhar machadiano. Profunda porque dirigindo-se para além das relações sociais e dos jogos de máscaras que constituem uma "outra" dimensão fundamental desse olhar, embora as últimas aspas sejam absolutamente necessárias, pois essas dimensões, vale a pena sublinhar novamente, estão aqui intimamente relacionadas. $E m$ todo caso, não é difícil reconhecer a importância que os temas ligados às "dimensões profundas" da existência pos- 
suem na produção literária de M achado. Em seus romances, onde se conjugam de forma direta à representação das relações so ciais, eles são quase sempre configurados sob o prisma da ironia. M as isso não significa que aquelas dimensões se reduzam à ironia, mesmo porque no contraste que estabelecem com a existência social é sobretudo a fragilidade desta o que se revela. É o que ocorre nos momentos em que Brás C ubas e B entinho, respectivamente nos episó dios do delírio e dos "olhos de ressaca", se vêem, se pasmam e se abismam diante de manifestações das forças mais primitivas e torrenciais da natureza.

Já na produção poética de M achado de Assis essa temática surge de formas, digamos assim, mais coladas à visão de mundo do escritor, o que evidentemente se relaciona ao fato da relação entre a subjetividade autoral e a expressão artística ser de um modo geral mais estreita na mediação realizada pelo eu lírico do que naquela instituída pelo narrador ficcional; e ainda que a própria poesia de $\mathrm{M}$ achado contenha jogos de espelhos e elementos irônicos, também a ela isso é aplicável. A esse respeito, um dos exemplos mais significativos é o soneto " $M$ undo interior", das O cidentais (2).

O uço que a natureza é uma lauda eterna

D e pompa, de fulgor, de movimento e lida,

U ma escala de luz, uma escala de vida

D e sol à ínfima luzerna.

O uço que a natureza, - a natureza externa, -

Tem o olhar que namora, e o gesto que intimida,

Feiticeira que ceva uma hidra de L erna

Entre as flores da vela Armida.

E contudo, se fecho os olhos, e mergulho

D entro em mim, vejo à luz de outro sol, outro abismo

Em que um mundo mais vasto, armado de outro orgulho,

Rola a vida imortal e o eterno cataclismo,

E, como o outro, guarda em seu âmbito enorme,

U m segredo que atrai, que desafia, - e dorme.

$\mathrm{N}$ ão constitui novidade o fato de que a "N atureza mãe e inimiga" , a Pandora do delírio de Brás Cubas, já se prefigura em alguns dos poemas que, embora reunidos somente em 1900 nas 0 ci dentais, foram escritos entre o final da década de 1870 e o início da seguinte, cerca de uma década portanto antes das M emórias póstumas (3). Eugenio Gomes foi um dos críticos que, numa espécie de "apêndice francês" a seu estudo das influências inglesas em M achado, chamou a atenção para esse fato, explorando alguns dos elementos da "filosofia da natureza" machadiana num paralelo com a poesia de Victor H ugo (4). 
Esses dois aspectos da leitura de Gomes nos interessam diretamente, na medida em que também o presente trabalho tem como tema, ou pelo menos como eixo de articulação, a influência de H ugo sobre a poesia machadiana no que diz respeito à mesma questão. Em suas aproximações, Gomes busca apontar não só influências gerais de $\mathrm{H}$ ugo sobre $\mathrm{M}$ achado como algumas fontes mais ou menos precisas da concepção machadiana da natureza. D e um modo geral, aliás, tais relações e indicações de fontes são bastante convincentes. Ao mesmo tempo, porém, o núcleo de nossa abordagem tem um objetivo de certo modo alheio ao texto do crítico, quando não polêmico em relação a ele. Pois o fato é que Gomes não apenas se preocupa essencial e quase exclusivamente com as relações de identidade entre as visões dos dois poetas, praticamente ignorando suas diferenças, como constrói tais relações • "r meio de um movimento curioso: reduzindo a especificidade de $\mathrm{H}$ ugo àquilo que ele, Eugenio Gomes, parece tomar, ao longo de seu livro, como o dado fundamental da visão de mundo machadiana, ou seja, o "pessimismo" (5).

Assim, é sobretudo pela via de uma "filosofia negativa da vida" que se desenvolvem as relações traçadas por Gomes. Entretanto, os elementos de uma filosofia da vida ou da natureza que se podem reconhecer em $\mathrm{H}$ ugo nem de longe se esgotam no tipo de negativismo niilista ou quase niilista que o crítico atribui, corretamente ou não, a M achado. Em todo caso, existem diferenças importantes entre as "visões profundas" dos dois poetas que Gomes despreza ou ignora, ou pelas quais apenas resvala, e que merecem ser analisadas com algum cuidado. E isso não apenas para que se faça jus à especificidade das visões hugoanas, mas também porque tal esforço talvez possa contribuir para entrevermos uma concepção machadiana da natureza e da vida pelo menos em certos aspectos diversa das que têm sido comumente aceitas pela crítica - o que é, em última instância, o objetivo deste trabalho.

\section{0 utros abismos}

Certamente não foi por acaso que M achado de Assis deu o nome de 0 cidentaisa seu último livro de poesias. Como observa Eugenio Gomes, esse título "parece uma réplica às Orientais, de H ugo"; e realmente não é difícil perceber a efetividade desse diálogo, que no entanto nem de longe se restringe ao referido volume hugoano e nem mesmo à obra do poeta francês, dirigindo-se na verdade a um amplo leque de grandes autores ocidentais. Ainda assim, a importância dos temas e tratamentos poéticos de $\mathrm{V}$ ictor $\mathrm{H}$ ugo na construção do livro é evidente, sobretudo em seu conjunto de poemas iniciais, que se encerra com " $M$ undo interior" (ao qual se segue a tradução de "O corvo", de Poe), sendo esse diálogo certamente retomado em outros momentos, entre eles a homenagem explícita "1802-1885" e talvez o fecho da obra, o soneto "No alto".

D esse modo, a escolha do título parece apontar para duas direções complementares: de um lado, para uma idéia de síntese poético-filosófica - para a qual 
contribui o fato da obra ter sido lançada num volume que incluía os outros livros da poesia de $M$ achado, com as devidas supressões realizadas por ele mesmo -, construída a partir de homenagens a autores cuja influência no conjunto da obra machadiana é inegável; e de outro, para o diálogo como V ictor H ugo como uma espécie de corolário dessa síntese, o que evidentemente permite buscar nele uma das chaves da visão profunda do escritor brasileiro. Aliás, das relações traçadas por Gomes, algumas das mais significativas dizem respeito justamente a poemas pertencentes ao grupo de abertura das 0 ci dentais $M$ as não acompanharemos de perto essas relações, o que tomaria um espaço excessivo em nossa exposição; em vez disso, desenvolveremos as nossas próprias associações, tendo como ponto de partida o poema "M undo interior", que já foi aqui reproduzido.

A respeito desse poema, o crítico aponta apenas a existência de "vocábulos e expressões (...) que denunciam, de algum modo, a presença do fabuloso dicionário hugoano: 'lauda eterna de pompa', 'hidra de Lerna', 'abismo', ' um mundo mais vasto', 'eterno cataclismo', 'âmbito enorme', etc." . E ntretanto, a origem de "M undo interior" parece estar ligada a uma fonte mais específica: o poema " $\mathrm{Ce}$ qu'on entend sur la montagne", de Lesfeuillesd'automne(6). Também o poema de H ugo contém uma dicotomia entre o mundo exterior e o interior, este último denominado, como no soneto machadiano - o que certamente não é um acaso -, o outro abismo:

Et je rêvai longtemps, contemplant tour à tour,

A près le abîme obscur que me cachait la lame,

L'autre abîme sans fond qui s'ouvrait dans mon âme.

M as talvez um resumo de "C e qu'on entend...", poema bem mais extenso que "M undo interior", seja útil aos nossos objetivos. O poeta começa dirigindose ao leitor: "Avez-vous qualquefois, calme et silencieux, / M onté sur la montagne, en présence des cieux? / (...) / Aviez l'océan au pied de la montagne?" Logo depois, passa a descrever "ce qu'on entend" do alto da montanha: detém-se primeiro sobre o "bruit large, immense, confus, / Plus vague que le vente dans les arbres touffus, / Plein d'accords éclatants, de suaves murmures", ou seja, sobre a "musique ineffable et profonde" do oceano, música esta "Q ui, fluide, oscillait sans cesse autour du monde, / Et dans les vastes cieux, (...), / Roulait élargissant ses orbes infinites".

E m seguida distingue "deux voix", que "D e la terre et des mers s'épanchant jusqu'au ciel" : uma destas é ainda o rumor do oceano, que logo adiante é novamente descrito, agora como uma "voix joyeuse e pacifique", cantando "comme la harpe aux temples de Sion" e louvando "la beauté de la création"; a outra, porém, a que se eleva da terra, é o triste "murmure des hommes", descrito "comme un cri de coursier qui s'effare, / Comme le gond rouillé d'une porte d'enfer", entoando "malédiction, et blasphème, et clameur". E é depois de escutar o mur- 
múrio dessas duas vozes que o poeta olha para o abismo "que s'ouvrait dans mon âme", o que o leva à dolorosa interrogação que encerra o poema:

Et je me demandai pourquoi l'on est ici,

Q uel peut être aprés tout le but de tout ceci,

Q ue fait l'âme, lequel vaut mieux d'être ou de vivre,

Et pourquoi le Seigneur, qui seul lit à son livre,

M êle éternellement dans um fatal hymen

Le chant de la nature au cri du genre humain?

É evidente o tom dramático, de um dilaceramento tipicamente romântico, desse fecho, cuja tensão permanece irresolvida. M as seria precipitado extrair desse dado uma prova da predominância de uma visão "pessimista" em H ugo. Em primeiro lugar, porque o desalento que se exprime nesses versos não anula 0 sentimento de plenitude que o poeta extrai do "chant de la nature"; segundo, porque tal fecho dramático constitui, a rigor, uma exceção em sua poesia. N ão que a tensão dramática não seja de fato uma constante em $\mathrm{H}$ ugo; o que ocorre é que quase sempre ela se resolve pela submissão dos pólos em conflito a uma força superior, a uma força ordenadora, geralmente, embora nem sempre, identificada com a imagem de Deus. E tal "força superior" se manifesta e é nomeada nos versos de "Ce qu'on entend..." : ela é o Deus que escuta a voz da natureza e dos homens, Aquele que "peut dompter" as ondas do oceano, sobre as quais passa as mãos co-mo por sobre uma "crinière d'or". Ao grito angustiado dos homens, ao qual se soma o do poeta, no entanto, Ele permanece indiferente.

É outra, porém, a si-tuação em um poema de tema algo semelhante, embora com uma configuração de conflitos bastante diversa, na verdade quase invertida: "O céan", de La légen de des siécles (7). É praticamente certo o conhecimento desse poema por $M$ achado, inclusive porque ele é um dos que contêm a imagem da "hidra de L erna", também presente em "M undo interior". Em linhas gerais, seu núcleo constitui uma longa invectiva do oceano contra o homem e sua tentativa de domá-lo, reduzindo-o a um caminho tão submisso quanto as estradas da terra e os animais a que a humanidade impôs o seu jugo. Aqui, porém, a voz do oceano já não afina tão facilmente com as forças divinas; pelo contrário: é com arrogante aversão a qualquer domínio, a não ser o dos "quatre ventes", que ele se declara "le noir gouffre inculte", "la vaste mêlée", "La figure échevelée / De l'inconnu", "la tempête vierge / Qui peut briser / Caps et rochers comme verre", recusando-se, sobretudo, a ser um "auberge" para o homem. Enquanto isso, a este cabe agora o papel de representante dos desígnios celestes. E mbora 0 oceano 0 acuse - "ta marche est peu droite; / Ton commerce avide exploite/ Les flots mouvantes; L'âpre soif de l'or t'anime" -, é ele mesmo quem, ainda irado, reconhece em seguida: 
- Allez-vous-en! Je devine

$\mathrm{Q}$ u'on rêve une ère divine,

Fin des fléaux.

O n court sur l'onde aplanie.

On m'emploie à l'harmonie,

M oi, le chaos!

E é na qualidade de portador dos desígnios divinos que o homem adverte o oceano:

Tu cherches ton belluaire?

Gouffre, c'est Dieu!

- L'amour, c'est la loi suprême.

$L$ 'amour te vaincra toi-même.

Ton bruit est vain.

Pour que, caressant ta grève,

Ton hymne d'enfer s'achève

En chant divin,

- Pour que ton hurlement tombe,

II suffit que la colombe

$Q$ ui vient le soir,

O sombre gouffre d'écume,

L aisser tomber une plume

Sur ton flot noir.

Vale notar que a análise desse poema deve levar em conta sua posição no interior da monumental "epopéia da humanidade" em que se constitui La légende des siécles, e cujo objetivo, nas palavras do próprio $\mathrm{H}$ ugo, é nada menos que o seguinte:

Exprimer l'humanité dans une espèce d'oeuvre cyclique; la peindre successivement et simultanément sous tous ses aspects, histoire, fable, philosophie, religion, science, lesquels se résument en un seul et immense mouvement d'ascension vers la lumière (...). . "Préface de la première sé-

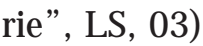

Tal movimento, como indica $\mathrm{H}$ ugo em seguida, teria como um de seus coroamentos o poema "La fin de Satan", que se segue a "O céan" e cujo assunto já se anuncia neste último ("Satan meurt, un autre empire / N aît..."): é, portanto, já desse contexto de redenção que ele participa, o que explica a posição particular que o homem assume nele. 
Em todo caso, menos do que essa posição, o que nos interessa aqui é o tipo de dicotomia que se revela de forma muito mais cristalina em "O céan", que parece informar toda a obra poética (e mesmo ficcional) de Victor H ugo e que, manifestando-se também no poema anteriormente analisado, embora de forma bem mais sutil, constitui um dos diferenciais mais relevantes no que tange às "filosofias da natureza" do escritor francês e de M achado de Assis. Tal dicotomia compõe-se, de um lado, por elementos identificáveis como forças caóticas da natureza e, de outro, por suas forças ordenadoras ou, talvez mais constantemente, pelo "princípio ordenador" que preside a elas. Ela se relaciona a tudo o que a visão de mundo de H ugo contém de teleológico e até teológico, e que, por estranho que possa parecer à sensibilidade de nossa época, constitui um dos fatores de força de sua poesia.

É verdade que essa dicotomia se manifesta de forma bem menos explícita e mais dialética em "Ce qu'on entend sur la montagne", onde a mesma música que o oceano "souffle, furieuse, aux bouches des clairons" é também um "chant de glorie" (8). Ainda assim, é apenas na medida em que se deixa "dompter" pelas mãos de D eus, em que presta homenagem e dá provas de sua submissão a Ele, diante de quem "par moments abaissait sa voix haute", que o oceano revelase digno de participar de Sua glória. Assim, ainda que não chegue a se constituir nos termos de uma polaridade rigidamente estabelecida, não há como deixar de ver aí um conflito entre as forças caóticas da natureza e uma força ordenadora que as preside, e cuja supremacia deve ser afirmada na mesma medida em que aquelas devem ser, pelo menos até certo ponto, refreadas. Em "Ce qu'on entend..." , é do fato do murmúrio caótico e dissonante dos homens e do abismo aberto na alma do poeta não poderem se afinar com essa força ordenadora que nasce a angústia desse último. Q uando, pelo contrário, constitui-se uma identidade entre o destino do homem e os desígnios divinos, aí se realiza plenamente aquela - para utilizarmos outra expressão hugoana - pi tiésuprême, da qual tanto esses desígnios quanto o olhar do poeta se fazem portadores.

$M$ as a essa altura já temos el ementos para voltarmos ao soneto de $M$ achado de Assis e avaliarmos seus pontos de ruptura em relação à visão de mundo expressa nos poemas de $\mathrm{H}$ ugo. U ma primeira e importante diferença entre " $\mathrm{M}$ undo interior" e "Ce qu'on entend..." é que no poema de M achado não há esse movimento de submissão das forças caóticas da natureza a uma "força ordenadora" superior que reconhecemos no do poeta francês. Em relação à "natureza externa", ainda que predominem as imagens ligadas a dimensões mais "positivas" da natureza, é sem conflito que ela contém tanto "o olhar que namora" quanto "o gesto que intimida". Em todo caso, não é essa natureza que tem a primazia no soneto machadiano, algo de que tanto a forma sutilmente irônica como ela é apresentada ("O uço que a natureza...") quanto a expressão "um mundo mais vasto, armado de outro orgulho", referente à "natureza interior", não deixam a menor dúvida. E em relação a esta, é mais do que evidente a predominância, aqui 
sim, al heia a qualquer ironia, das imagens caóticas, predominância esta que se mantém até 0 fim, onde tais imagens parecem se associar à da morte.

Ainda assim, e esta é a segunda diferença que queremos assinalar, o fecho do soneto machadiano não contém o tom dramático do poema de Hugo. É como "U m segredo que atrai, que desafia", que o poeta brasileiro encara o "eterno cataclismo" de seu "mundo interior". Em M achado, portanto, ao contrário do que ocorre em H ugo, não é apenas na medida em que se submetem aos elementos "positivos" e àquele sentido teleológico mais visível em "O céan" que as dimensões caóticas, soturnas e vorazes da vida são acolhidas no interior do esquema estético e "filosófico" do poeta. 0 fato do "mundo interior" descrito por $\mathrm{M}$ achado conter pelo menos um dos elementos que em $\mathrm{H}$ ugo costumam se associar às "forças ordenadoras" da natureza, ou seja, o sol, não desmente essa idéia, ajudando antes a reforçá-la, na medida em que atesta a relação dialética que os elementos caóticos travam com os ordenadores, sem, no entanto, que a hegemonia deixe de pertencer a eles.

Por outro lado, se a polaridade entre essas duas dimensões primordiais da existência se configura, na obra de H ugo, sob a hegemonia dessas a que chamamos de "ordenadoras", e que aqui ganham acentos claramente metafísicos, é preciso lembrar que raramente isso leva à completa recusa das forças caóticas da natureza ou dos elementos identificáveis a elas. 0 estabel ecimento de algum tipo de dialética entre elas e sua antítese, embora em graus variados, participa da própria teoria hugoana do sublime e do grotesco. U ma provável exceção é o poema "La chauve-souris" (O P, 456-457), das O des et ballades, onde 0 "triste oiseau" do título é associado a imagens fúnebres e até demoníacas ("L es filles de Satan t'invoquent sans remords..."). Aliado da noite, outra imagem hugoana que por vezes assume formas em maior ou menor grau negativas, o morcego tem um melancólico destino com o raiar do dia e, portanto, o restabelecimento da hegemonia das forças ordenadoras do mundo:

Et le jour te verra, dans le ciel exilée,

A mille oiseaux joyeux mêlée,

D 'un vol aveugle et lourd chercher en vain la nuit!

M as é preciso levar em conta o dado de que esse poema foi escrito em 1822, data anterior, portanto, ainda que em apenas cinco anos, ao "Prefácio" a C romwell. Bem mais revelador da visão de mundo amadurecida de Victor $\mathrm{H}$ ugo é o poema "Le crapaud" (LS, 655-659), de La légende des siécles, cuja temática guarda certa semelhança com o anterior. Aqui é o sapo que é descrito como um "monstre chétif, louche, impur" e associado a toda sorte de imagens repulsivas. No entanto, já no início desse poema de estrutura narrativa, o sapo nos é apresentado a contemplar "la grande auréole solaire", e é a partir dessa imagem que o poeta argumenta, em sua defesa: 
Peut-être le maudit se sentait-il béni;

Pas de bête qui n'ait un reflet d'infini;

Pas de prunelle abjecte et vile que ne touche

L'éclair d'en haut, parfois tendre et parfois farouche;

Pas de monstre chétif, louche, impur, chassieux,

Q ui n'ait l'immensité des astres dans les yeux.

N os versos seguintes, a hediondez do animal se amplia à medida em que ele é sucessivamente pisoteado por vários transeuntes, até que um grupo de crianças - entre as quais, segundo o poeta, ele próprio se incluía - depara-se com ele e decide: " - Tuons ce vilain animal, / Et, puisqu'il est si laid, faisons-lui bien du mal!" . Segue-se, então, a descrição de um verdadeiro festival de sadismo promovido pelos meninos, entremeada de comentários do autor censurando sua crueldade infantil:

- H élas! ayons des buts, mais n'ayons pas de cibles;

$Q$ uand nous visons un point de l'horizon humain,

A yons la vie, et non la mort, dans notre main.

Ao final, porém, no momento em que o futuro poeta se prepara para esmagar o sapo, uma súbita intervenção o detém:

Alors, lâchant la pierre échappée à sa main,

U n des enfants - celui qui conte cette histoire -

Sous la voûte infinie à la fois bleue et noire,

Entendit une voix qui lui disait : Sois bon!

E é dessa voz que o poeta extrai e nos comunica a seguinte "lição":

O sage,

La bonté, qui du monde éclaire le visage,

La bonté, ce regard du matin ingénu,

La bonté, pur rayon qui chauffe l'I nconnu,

Instinct qui dans la nuit et dans la souffrance aime,

Est le trait d'union ineffable et suprême

Q ui joint, dans l'ombre, hélas! si lugubre souvent,

Le grand ignorant, l'âne, à D ieu, le grand savant.

Podemos reconhecer aí, concentrados, os movimentos que identificamos nos dois poemas analisados anteriormente: a dialética entre elementos ordenadores e caóticos, ou "sublimes" e "grotescos", em que estes prestam reverência àqueles (o animal hediondo deslumbrado com o céu: "I'horreur contemplait la splendeur" ), e um movimento mais amplo de redenção graças a uma intervenção 
divina. Esse duplo movimento contém a essência da pitié suprême hugoana, que é o sentimento pelo qual a ordem, a vida e o sublime simultaneamente acolhem e redimem o caos, a morte e o grotesco.

À exceção, talvez, de alguns exemplos de sua produção inicial (9), a obra poética de $M$ achado de Assis desconhece ou mesmo recusa conscientemente esse movimento, principalmente em seus aspectos teológicos e teleológicos. D essa recusa, um dos exemplos mais radicais é um poema, também das 0 ci dentais, cuja lembrança é inevitável diante do "Le crapaud" hugoano: "Suave mari magno" (OC , 161). Embora seja mais difícil falarmos em fonte ou intertexto nesse caso, pode-se talvez cogitar uma inspiração mais ou menos direta do poema de $\mathrm{H}$ ugo na concepção do de $M$ achado. N este, o assunto é a morte de um cão por envenenamento, cena diante da qual passam vários transeuntes, cada um dos quais se detém, observando-a "Como se lhe desse gozo / Ver padecer". São esses versos que encerram o soneto. $M$ as tampouco aqui pesa sobre a morte algum tipo de estigma, moral ou metafísico, como se percebe pela própria descrição da agonia do animal:

Arfava, espumava e ria.

D e um riso espúrio e bufão,

Ventre e pernas sacudia

$\mathrm{N}$ a convulsão.

À morte algo voluptuosa do cão soma-se a volúpia no olhar dos transeuntes (também presente, diga-se de passagem, no dos meninos de $\mathrm{H}$ ugo); mas mesmo esse possível sentido irônico-crítico não chega a investir as dimensões caóticas e dissolutivas da vida de algum estigma.

E m outros momentos, a própria vida é fundamentalmente definida, e novamente sem nenhum estigma, segundo os termos dessas dimensões, do que os versos finais de "U ma criatura" são o exemplo mais evidente:

Pois essa criatura está em toda a obra;

Cresta o seio da flor e corrompe-Ihe o fruto;

E é nesse destruir que as suas forças dobra.

Ama de igual amor o poluto e o impoluto;

Começa e recomeça uma perpétua lida,

E sorrindo obedece ao divino estatuto.

Tu dirás que é a morte; eu direi que é a Vida.

Certamente não é gratuita a utilização do adjetivo "divino" no penúltimo desses versos inegavelmente despidos de ironia (10). C aso zelasse pela visão pessimista que parte da crítica Ihe atribui, M achado não teria dificuldades em encontrar uma expressão mais adequada a ela sem violar a métrica: "sinistro", por 
exemplo. Ao mesmo tempo, é justamente às imagens dissolutivas e caóticas, e não em oposição a elas, não "superando-as", que se associa o adjetivo.

Assim, pode-se dizer que $M$ achado inverte a equação que $H$ ugo estabelece entre as dimensões ordenadoras e caóticas da existência: pelo menos é o que poemas como "M undo interior" e "U ma criatura", ambos de significação evidente enquanto expressão de uma "filosofia" da vida ou da natureza, parecem revelar. À semelhança da aliança que Victor H ugo estabelece com certas " forças ordenadoras" , a obra de M achado é marcada pelo sentimento, não unilateral, porém mais direto, de um vínculo com as dimensões caóticas da existência. Tal sentimento - um sentimento autoconsciente, e que portanto é também idéia parece se delinear desde a produção inicial do escritor e configura-se plenamente em sua "segunda fase", um processo que evidentemente não podemosacompanhar aqui.

0 utro conhecido poema machadiano, visto geralmente como uma alegoria da velhice, talvez contenha, mais do que isso, uma metáfora desse vínculo. Trata-se de "No alto" (O C , 473), justamente o soneto que encerra as $\mathrm{O}$ cidentais, e onde, se não uma intertextualidade com "Ce qu'on entend...", pelo menos outra apropriação do tratamento antitético que o poeta francês confere ao motivo romântico do alto da montanha também parece plausível - e isso a despeito do diálogo explícito com Shakespeare, aliás uma referência não menos importante para $\mathrm{H}$ ugo:

O poeta chegara ao alto da montanha,

E quando ia descer a vertente do oeste,

Viu uma cousa estranha,

U ma figura má.

Então, volvendo o olhar ao subtil, ao celeste,

Ao gracioso Ariel, que de baixo o acompanha,

$\mathrm{N}$ um tom medroso e agreste

Pergunta o que será.

Como se perde no ar um som festivo e doce,

$\mathrm{O}$ u bem como se fosse

U m pensamento vão,

Ariel se desfez sem Ihe dar mais resposta.

Para descer a encosta

O outro Ihe deu a mão.

Vale lembrar que, em A tempestade, Próspero é não só um personagem como também, por vezes, uma espécie de porta-voz do poeta, prestando-se a uma função metalingüística da qual talvez $M$ achado também tenha se valido. N esse sentido, esse Próspero "atualizado" em M achado - um Próspero privado de sua autoridade semidivina, a quem Ariel já não atende nem responde, e a quem 
C alibã oferece ajuda, como a Ihe propor uma aliança - parece cristalizar em si a imagem de uma espécie de demiurgo do caos, que assume como tarefa dar forma a um mundo caótico mas que ao mesmo tempo se reconhece ironicamente como parte dele, e que portanto não tem a ilusão de imprimir-lhe sentidos absolutos. I magem que aliás também se entrevê na autodefinição daquele amigo de Rubião, mas decerto revelando algo da práxis do autor, como um "arquiteto de ruínas" (11).

$M$ as se os elementos caóticos, destrutivos ou dissolutivos da vida não são, na obra madura de M achado, subsumidos numa "força ordenadora" superior, em alguns momentos eles mesmos, ou a própria morte, como que servem de abrigo à dissolução que se opera na vida. "A Artur de O liveira, enfermo" (O C, 152-153), outro poema pertencente ao grupo de abertura das 0 ci dentais, é muito esclarecedor nesse sentido. Também aqui o diálogo com $\mathrm{H}$ ugo parece presente: embora o "poeta enorme" do início do poema se revele ao final como sendo o próprio Artur de O liveira, vários indícios sugerem que é num jogo com a imagem de Victor H ugo que M achado constrói a do amigo. É difícil, por exemplo, não reconhecer o poeta francês nessa descrição, um pouco imponente demais para se referir de forma direta ao escritor gaúcho de modesta produção, sem falar na alusão a um "orientalismo" que talvez ele tenha cultivado, mas pelo qual muito mais se celebrizou o próprio H ugo:

O ra do fuste, ora da ogiva,

Sair parece;

O ra o D eus do ocidente esquece

Pelo deus Siva...

E é mais uma vez a imagem do poeta no alto montanha que ressurge quando finalmente $M$ achado dá a entender a quem se referem tais versos, ao mesmo tempo que aconselha o amigo enfermo:

Se não sabes quem ele seja

Trepa de um salto,

Azul acima, onde mais alto

A águia negreja;

E ntão, olha de cima posto

Para o oceano,

Verás num longo rosto humano

Teu próprio rosto.

E hás de rir, não do riso antigo,

Potente e largo,

Riso de eterno moço amigo,

$M$ as de outro amargo, 
Como o riso de um deus enfermo

Q ue se aborrece

D a divindade, e que apetece

Também um termo...

Aqui, como se vê, nenhuma imagem propriamente redentora se segue à idéia da morte, com a qual o poeta defronta o amigo. Ao mesmo tempo, porém, a própria morte é apresentada, senão como um bem, ao menos como um alívio, na forma de uma irônica consolação; em to do caso, com um espírito bem diverso da dúvida atroz sobre o destino do homem com que se encerra "Ce qu'on entend..." ("Q uel peut être aprés tout le but de tout ceci, / Que fait I'âme, lequel vaut mieux d'être ou de vivre..."). N ão são poucos, aliás, os momentos em que a morte, o sono ou o esquecimento tomam esse sentido "consolador" na obra de $M$ achado. Ele já está presente, por exemplo, no poema de abertura das Crisálidas(1864), "M usa consolatrix"; e também no delírio de Brás C ubas, vale a pena lembrar, Pandora define o sono como "o maior benefício das minhas mãos" (12).

M as uma vantagem particular de nos determos sobre " A Artur de O liveira, enfermo" é que esse poema nos deixa perceber de forma mais clara, naturalmente admitindo-se o jogo que julgamos ter reconhecido há pouco, como $\mathrm{M}$ achado leu e assimilou a obra de Victor $\mathrm{H}$ ugo em sua maturidade. $\mathrm{N}$ ele, a "hierarquia" que 0 autor das 0 ci dentai sestabelece entre as dimensõ es caóticas e ordenadoras da natureza e as imagens ligadas a uma ou outra dá lugar a uma relação mais plana e igualitária:

Gosta do estrépito infinito,

Gosta das longas

Solidões em que se ouve o grito

D as arapongas;

$E$, se ama o lépido besouro,

Q ue zumbe, zumbe,

E a mariposa que sucumbe

$\mathrm{N}$ a flama de ouro,

Vaga-lumes e borboletas,

D a cor da chama,

Roxas, brancas, rajadas, prestas,

$\mathrm{N}$ ão menos ama

O s hipopótamos tranqüilos,

E os elefantes,

E mais os búfalos nadantes

E os crocodilos, 
Como as girafas e as panteras

O nças, condores,

Toda a casta de bestas-feras

E voadores.

Q uanto às razões dessa particularidade, é evidente que são extremamente complexas, e tanto dizem respeito às diversas outras influências literárias de $\mathrm{M}$ achado, quanto às particularidades de nosso desenvolvimento periférico e à própria dialética histórica das formas e dos conteúdos literários, to dos estes problemas sobre os quais também não podemos nos deter aqui. Em todo caso, os elementos que apontamos parecem suficientes para demonstrar que, longe de se relacionarem apenas pela via de um certo "pessimismo", as "visões profundas" de $\mathrm{H}$ ugo e $\mathrm{M}$ achado constituem, na assimilação daquele por este, uma dialética na qual também o sentimento de plenitude da poesia hugoana toma parte, recebendo no entanto outra configuração na de M achado; e isso talvez esteja ligado de forma mais íntima do que se tem reconhecido à constituição da "fase madura" e mais bem realizada do escritor brasileiro.

\section{D e uma "piedade suprema" a uma "suprema ironia"}

Sem dúvida, um dos riscos de se descrever a "filosofia da natureza" machadiana nos termos em que fizemos acima é associá-la a uma visão conformista da existência. Tal risco, no entanto, só se concretiza na medida em que se des- preza tudo o que a obra de M achado comporta, sobretudo em suas narrativas, em termos de ironia crítica, para a qual, como dizíamos no início, sua "visão profun- da" e seu sentimento de um vínculo com as forças caóticas da natureza terminam por contribuir.

A final, se por vezes o instante lírico pode fixar o sentimento desse vínculo na imagem de uma unidade plena ou de uma empatia consoladora (mas não redentora, o que é muito diferente), a própria complexidade da diegese narrativa coloca o problema em outros termos. Q ue se recorde, por exemplo, em Dom Casmurro, o episódio da morte de M anduca (13) - o jovem leproso que, nas palavras de Bentinho, " para entrar na sepultura, gastou três anos de dissolução, tão certo é que a natureza, como a história, não se faz brincando" - e onde podemos encontrar al guns dos mais impressionantes exemplos da espécie de piedade egoísta, ou de cinismo inconsciente, do narrador. Já no momento em que nos revela e manifesta seu alívio pela morte de Ezequiel, o cinismo de Bentinho é bem menos inconsciente; a esse respeito, basta lembrar a frase que encerra 0 episódio: "A pesar de tudo, jantei bem e fui ao teatro" (DC, 345).

$M$ as nem por isso deixa de haver um estranho lirismo na trajetória desse jovem de paternidade indefinida, que, quando menino, como que trazendo dentro de si da forma mais pura a natureza voraz das M emóriaspóstumas, se comprazia em ver um rato sendo devorado, e quando adulto se torna arqueólogo. Do início 
ao fim marcada pela idéia da morte e das ruínas, sua trajetória não deixa de fazer jus a seu epitáfio: "Tu eras perfeito nos teus caminhos" (DC, idem). Ainda aqui, portanto, o parafuso dá mais uma volta, pois, como se sabe, a suprema ambigüidade da ironia em D om Casmurro destrói muitas vezes o olhar do narrador, mas não a essência do que ele toca (e, afinal, mesmo sob as palavras perversas de Bentinho talvez possamos pressentir uma tristeza inconfessável).

Entretanto, nada disso significa que o peso da morte do rapaz se anule, assim como tampouco o lirismo igualmente estranho com que é narrada a morte de Flora, em Esaú e Jacó, a minimiza. Aqui, por um lado, é evidente a idéia de uma morte "consoladora" (num episódio que, aliás, lembra o da morte de José Dias em D om Casmurro):

Flora acabou como uma dessas tardes rápidas, não tanto que não façam ir roendo as saudades do dia; acabou tão serenamente que a expressão do rosto, quando lhe fecharam os olhos, era menos de defunta que de escultura. As janelas, escancaradas, deixavam entrar o sol e o céu (14).

N o entanto, é sem dúvida com a mais sinistra e dolorosa ironia que M achado narra o episódio da "reconciliação" dos gêmeos, quando eles se cumprimentam "por cima da cova" da jovem travando o seguinte diálogo:

- Ela nos separou, disse Pedro; agora, que desapareceu, que nos una.

Paulo confirmou com a cabeça.

- Talvez morresse para isso mesmo, acrescentou. (EJ, 142)

E se a imagem da "sombra de Flora" inscrevendo "aquela promessa de reconciliação nas tábuas da eternidade" parece reinvestir a cena de um lirismo até metafísico, a precariedade da amizade dos irmãos, logo dissolvida - quão frágeis aquelas "tábuas" diante dos conflitos mundanos! - não deixa dúvidas de que também sobre tal imagem paira a mesma e tristíssima ironia: o "sacrifício" da jovem fora em vão; $M$ achado, portanto, não o legitima.

D esse modo, o sentimento de um vínculo com as forças caóticas da natureza parece se ligar, em M achado, a um duplo movimento. Primeiro, ele se traduz enquanto sentimento e potência apreensiva dos conflitos e contradições de um mundo caótico, em decomposição, de seres sedentos que se engalfinham, digno daquela "espécie de troça concentrada e filosófica" que o "grunhir dos porcos" um dia sugere a Bentinho (DC, 342). Segundo, ele é o sentimento de um caos mais primordial e profundo, e que soma àquela potência apreensiva uma potência compreensiva, ao mesmo tempo que a resguarda do niilismo. J ustamente por isso a ironia machadiana pode sustentar até o fim os conflitos com que nos defronta, não se rendendo, por exemplo, às soluções conciliatórias de um Voltaire - sem dúvida uma de suas principais fontes (15), e onde também há um forte sentimento dissolutivo -, como no "il faut cultiver notre jardin" com que o C andidese encerra. 
E m suma, pode-se dizer que aquele sentimento participa da configuração de uma "suprema ironia" no olhar e no sentimento da vida na práxis narrativa machadiana: uma ironia tão crítica quanto comprensiva, na qual o escritor encontra o "lugar de força" adequado para dar configuração plena a seu universo humano e social. No entanto, isso não significa que esse sentimento se esgote nesses dois aspectos, ou seja, o crítico e o compreensivo. Antes, ele não deixa de conter ou se desdobrar em outros sentimentos. Assim, não será surpresa se ele nos deixar entrever, nessa breve passagem de Esaú e Jacó, uma dimensão que ainda hoje escorre por entre os dedos da crítica:

O mar estava crespo. Aires começou a passear ao longo do terraço, ouvindo as ondas, e chegando-se à borda, de quando em quando, para vê-las bater e recuar. Gostava delas assim; achava-Ihes uma espécie de alma forte, que as movia para meter medo à terra. A água, enroscando-se em si mesma, dava-Ihe uma sensação, mais que de vida, de pessoa também, a que não faltavam nervos nem músculos, nem a voz que bradava as suas cóleras. (EJ, 89)

Talvez se possa vislumbrar aí, nesse mar com o qual Aires se sente irmanado, nesse mar crespo e insubmisso - e não alisado pelas mãos de Deus, como aquele do poema de $\mathrm{H}$ ugo - , uma revolta de raízes historicamente mais profundas, mas nem por isso de alcance menos universal, do que se tem porventura reconhecido em $M$ achado; uma revolta cuja vitalidade, para além de qualquer niilismo ou mesmo ironia, quem sabe ainda se venha a reconhecer como uma das seivas mais fortes, e por isso mesmo tampouco coagulada pelo ressentimento, de suas melhores obras.

N otas

1 Para nos atermos a exemplos mais ou menos recentes, ou seja, de meados do século XX para cá, são referências obrigatórias, entre as interpretações históricas e sociológicas, as de Raymundo Faoro, R oberto Schwarz e J ohn G ledson; entre as psicológicas (no caso, de caráter biográfico), a de Lúcia M iguel Pereira; entre as fiIosóficas, as de Eugenio Gomes e Afrânio Coutinho; entre os estudos de fontes e influências, os de Gomes (inglesas) e Gilberto Pinheiro Passos (francesas); entre as leituras de cunho mais estrutural, a de D irces Côrtes Riedel, sobre o tempo nos romances de $\mathrm{M}$ achado; já nas análises de Alfredo Bosi, várias dessas perspectivas se conjugam no desvelamento progressivo de uma certa "genealogia do olhar machadiano".

2 M achado de Assis. Obra completa. Rio de Janeiro, Aguilar, 1994, v. 3, p. 153. $\mathrm{D}$ aqui em diante designado por OC.

3Cf. CURVELLO, M ario. "Falsete à poesia de M achado de Assis", in BO SI , Alfredo 
et al. (org.). Machado de Assis. São Paulo, Ática, 1982, p. 493. Em relação a "M undo interior", entretanto, a indicação do quadro composto por Curvello é apenas "pós-1881".

4 GOM ES, Eugenio. "U ma fonte francesa (Victor H ugo)", in M achado de A ssisinfluênciasinglesas. Rio de J aneiro, Pallas/ M EC, 1976. Daqui em diante designado por U F.

5 D uas exceções, mas que não chegam a afetar a perspectiva geral de $G$ omes, na qual o pessimismo se encontra "à raiz do pensamento hugoano" (p. 111), na medida em que dizem respeito a aspectos muito pontuais, são as comparações entre os poemas "Círculo vicioso" e "Abîme" (p. 106-07) e o conto "O imortal" e o poema "Le Satyre" (p. 119-20).

6 H U GO , Victor. Oeuvres poétiques. Paris, Gallimard, 1964, v. 1, p. 726-28. D aqui em diante designado por $\mathrm{O} P$.

7 H U GO, Victor. La légende des siécles Paris, Gallimard, 1950, p. 537-49. D aqui em diante designado por LS.

8 Por outro lado, em outros momentos as dimensões caóticas ou soturnas da natureza chegam a ser investidas de um estigma metafísico: já em "O céan", pela própria associação com Satã, isso é visível; o mesmo ocorre não só com o mesmo oceano como sobretudo com a noite, no poema de Toutela lyre justamente denominado "N uit". E é a ela que se liga a angústia, similar à de "C e qu'on entend...", que o poeta exprime nos últimos versos: "Q ue se passe-t-il de terrible / Q ui fait que l'homme, esprit banni, / A peur de votre calme horrible, / 0 ténèbres de I'infini?" (Toutela lyre. Paris, Charpentier et Fasquelle, s/ d., v. 1, p. 136-39.)

9 Por exemplo, em "Luz entre sombras" e em "Sombras", ambos das Falenas(1870). N este último, as imagens funestas dão lugar ao apelo do poeta: "Corre sobre 0 passado impenetrável véu; / O lha para o futuro e vem lançar-te ao céu." Cf. O C, p. 46.

10 C aso haja alguma dúvida a esse respeito, basta constatar a proximidade temática do poema com o já referido "Luz entre sombras", das Falenas, que se encerra com esses versos: "D or que se transforma em glória, / M orte que se rompe em vida". Aqui, um certo estigma negativo ainda paira sobre as imagens caóticas, sobretudo a da "noite medonha e escura", estigma só superado na medida em que o poeta se lembra disso que exprimem os versos acima. 0 dado significativo para nosso argumento, porém, é a forma ainda mais inequivocamente alheia à ironia, porque de um "panteísmo" mais convencional ( $\mathrm{e}$, inclusive, mais afeito ao que por vezes se pode reconhecer em H ugo), como nele surge a dialética morte/ vida. O utros versos de "A criatura", como "Gosta do colibri, como gosta do verme, / E cinge ao coração o belo e o monstruoso", caberiam em "A Artur de O liveira, enfermo", também das 0 cidentais, e onde qualquer sentido crítico-irônico está igualmente ausente. $M$ as sobre esse poema nos deteremos logo adiante.

11 ASSIS, M achado de. QuincasBorba. São Paulo, FTD, 1992, p. 47. 
12 ASSI S, M achado de. M emórias póstumas de Brás Cubas. São Paulo, Abril Cultural, 1978, p. 25. Daqui em diante designado por M P. Cf. também o elogio ao sono em "H oras vivas", das Crisálidas. "D orme: se os pesares / Repousares, / Vês? - por estes ares / Vamos rir; / M ortas, não; festivas, / E lascivas, / Somoshoras vivas/ De dormir. -" (OC, 27; grifos do autor).

13 ASSI S, M achado de. D om Casmurro. São Paulo, Abril Cultural, 1978, p. 28289. Daqui em diante designado por DC.

14 M achado de Assis. Esaú ejacó. Rio de Janeiro, Ediouro, s/ d, p. 138. Daqui em diante designado por EJ. Entre outras coisas, essa passagem parece sugerir, na comparação do rosto de Flora com uma estátua, a única dimensão da realidade em M achado na qual as "forças ordenadoras" da existência se sobrepõem de forma duradoura às "caóticas" : a arte, que, praticada pelas próprias mãos humanas, visa subtrair o nome dos homens do esquecimento, mas não resguardá-los da inevitável dissolução no fluxo da vida. É esta, afinal, a "imortalidade" conferida a Alencar ("A Alencar", OC , 163), Camões ("Camões", O C , 164) e H ugo ("18021885", O C , 165), algo que o final dos versos dedicado ao primeiro desses autores deixa bem claro: "Porque o tempo implacável e pausado, / Q ue o homem consumiu na terra fria, / N ão consumiu o engenho, a flor, o encanto...".

15 Talvez não seja excessivo cogitar, por exemplo, que o fecho das M emórias póstumas- "N ão tive filhos, não transmiti a nenhuma criatura o legado da nossa miséria" (M P, 173) - tenha como inspiração o episódio em que Pangloss narra a "genealogia" de sua doença venérea, e que se encerra com a seguinte frase: "Pour moi, je ne la donnerai à personne, car je me meurs" (Voltaire. Candide ou l'optimisme. Paris, Librio, 1998, p.16.).

Ravel Giordano Paz é mestre em Teoria e H istória da Literatura pelo Instituto de Estudos da Linguagem da U nicamp e doutorando no Departamento de Letras C lássicas e Vernáculas da U SP. 